${ }^{1}$ Department of Surgical, Oncological and Oral Sciences, University of Palermo, Palermo, Italy.

${ }^{2}$ Prosthodontics Unit, School of Dentistry, CNEC Faculty of Santo Angelo, RS, Brazil.

${ }^{3}$ Department of Biomedical Sciences and Neuromotor, Division of Prosthodontics, Alma Mater Studiorum University of Bologna, Bologna, Italy.
Corresponding author: Vinicius Felipe Wandscher Franciscan University, Brazil viniwan@hotmail.com

Received: March 20, 2020 Accepted: September 26, 2020

\section{Retention strength of ball-attachment titanium post for removable partial denture or overdenture}

\author{
Dario Melilli ${ }^{1}$, Vinicius Felipe Wandscher ${ }^{2}$, Leonardo \\ Ciocca $^{3}$ (D), Giuseppe Currò ${ }^{1}$, Candida Parisi ${ }^{3}$, Giuseppe \\ Gallina ${ }^{1}$ Paolo Baldissara ${ }^{3}$
}

Aim: To evaluate the retention of an endodontic titanium post with a spherical head for removable partial denture or overdenture attachment according to surface treatment type. Methods: Sixty healthy single-rooted teeth, sectioned at the enamel/cementum junction, were treated endodontically and steadily fixed in the embedding acrylic resin. The titanium posts were subdivided into four groups: control, no surface treatment (Ctrl); posts with macroretentive grooves (MR); air abrasion of the post surface (AB); and posts with macro-retentive grooves and air abrasion of the post surface $(M R+A B)$. The posts were luted in the root canal using self-adhesive dual resin cement. Pull-out testing was performed using a universal testing machine until complete detachment was achieved. After pull-out testing, the metallic posts were examined under an optical microscope and the failures were classified based on the cement distribution pattern on the extracted posts: 0 , no cement left on the post (cement/post failure); 1, post surface partially covered by adhered cement (post/cement and dentin/cement mixed failure); 2 , post surface completely covered by cement (dentin/cement failure). The retention data were analyzed by one-way ANOVA, Bonferroni-Dunn test $(p<0.05)$ and Weibull analysis. Results: $A B$ showed the highest retention value (485.37 \pm 68.36$)$, followed by MR+AB ( $355.80 \pm 118.47)$, MR (224.63 \pm 42.54$)$ and Ctrl (113.12 \pm 51.32$)$. AB and MR showed the highest Weibull moduli. Conclusions: The data indicated that air abrasion alone could significantly increase the retention of titanium posts/attachments for use with overdentures or removable partial denture.

Keywords: Air abrasion, dental. Cementation. Denture retention. Surface Properties. 


\section{Introduction}

The classic tooth-supported overdenture consists of a complete denture anchored by single attachments to two or more natural teeth that act as bearing and retention points. The attachment, cemented in the root canals, can be used for retention of overdentures or removable partial dentures (RPD). Rehabilitation therapy with these anchorage methods could increase retention and stability compared to conventional RPDs (retained by clasps) ${ }^{1,2}$, and have aesthetic advantages due to the absence of any visible metallic clasps. This procedure is a simple, economic and conservative solution, which retains the principles and advantages of classic overdentures ${ }^{1,2}$.

The choice and cementation of posts in root canals are important considerations for the tooth-supported overdenture. Clinically, at least two options are available, i.e. prefabricated or cast posts. Although prefabricated posts present limitations of inadequate intraradicular morphology and reduced post space, they also have a number of advantages, including low cost, removal of less dentin (thus reducing the risk of root fracture) and a rapid clinical procedure ${ }^{3}$. Titanium is the metal of choice as it has excellent biocompatibility, good cement adhesion and high resistance to wear ${ }^{4}$.

Post retention depends on the morphology, size and surface texture of the posts ${ }^{5}$. In particular, parallel posts are more retentive than tapered posts, but they require more extensive and specific root canal preparation. While a longer post length ensures better retention, its diameter has little influence on the retention force ${ }^{5}$.

Moreover, it has been reported that retention is greater for threaded than smooth posts $^{5-10}$. Therefore, dentists should be aware of the risk of debonding of these posts, manifested as adhesive failure between intraradicular dentin, cement and/or post. Historically, the gold standard for cementing posts was zinc oxyphosphate followed by glass ionomer cements. After the introduction of composite resin, it became possible to increase adhesion and retentive forces, to reduce solubility and minimise the risk of microfractures ${ }^{11-19}$. The best results have been obtained by using adhesive systems associated with resin cements. The clinical success of resin cements is due to the mechanical properties of these materials, such as high flexural strength, compression strength, and elastic modulus, and adhesion to dental tissues ${ }^{20,21}$.

Both post/cement and dentin/cement interfaces are critical for the cementation of posts, especially when the post surface is smooth. In this case, retention can be increased by surface treatment of the post. Most studies have evaluated the retention or adhesive strength of fibre posts; there have been few studies regarding cementation techniques and surface treatment of metallic posts.

Therefore, this study was performed to evaluate the retention (pull-out) and interfacial adhesive failure of intraradicular posts with a spherical attachment (Pivot Block; Rhein83, Bologna, Italy) and cemented with a self-adhesive resin cement, according to different surface treatments; the reliability of the treatments was also assessed. The null hypothesis was that there would be no difference in retention between the groups $(a=0.05)$

\section{Materials and methods}

All described procedures comply with the Internal Ethical Committee guidelines, approved on 17/02/2016 (University Hospital "P. Giaccone" of Palermo, approval no. 2/2016). Sixty 
healthy single-rooted human upper incisors and lower premolars, extracted for periodontal or orthodontic reasons, were selected according to the following inclusion criteria: monoradicular teeth without caries and without endodontic treatment; absence of fractures; radicular length of at least $12 \mathrm{~mm}$; and radicular canal diameter inferior to the post size. After removing the residual soft and hard tissues using an ultrasonic scaler, the teeth were stored in $0.5 \%$ chloramine for 3 days, immersed in distilled water at $4^{\circ} \mathrm{C}$ for 2 days to prevent dehydration ${ }^{22}$, and then maintained in $0.02 \%$ thymol solution.

The teeth were sectioned using diamond burs at the cervical level of the enamel/ cementum junction (ECJ). Mechanical chemical preparation of the radicular canal was performed using 10-15 Proglider hand instruments (Dentsply Maillefer, Ballaigues, Switzerland) and $2.5 \%$ sodium hypochlorite. The post space was then standardised to a size of $10 \mathrm{~mm}$ using a customised drill (Mooser, A01MOG; Rhein 83, Bologna, Italy).

Macro-retentions were performed on the external surface of the roots by using a diamond bur (881.141.014; Komet Dental, Lemgo, Germany) attached to a high-speed handpiece, to enhance retention in resin material for the retention test. The teeth were embedded in resin cylinders (Tecnovit 4071, Heraeus Kulzer, Hanau, Germany) using a friction-grip mounting pin inserted in the root canal, then the pin head, along with the connected dental root, was mounted in a poly-vinylsiloxane cylindrical jig. The jig was securely placed in the PTFE mould until polymerization of the liquid resin around the root was reached. The goal was to maintain the axis of the root canal, then the axis of the luted titanium post, aligned with the direction of the pulling force, that actually was coaxial to the resin cylinder (Fig. 1) The Pivot Block posts were divided into four groups according to surface treatment (Fig. 2): control posts without surface treatment (Ctrl); posts with semi-circular macro-retentive grooves $0.4 \mathrm{~mm}$ deep made using a diamond bur (diameter, $0.8 \mathrm{~mm}, 835.107 .008$; Komet Dental) at 3, 5 and $7 \mathrm{~mm}$ from the coronal portion of the post (MR); air abrasion of the post surface with alumina $\left(\mathrm{Al}_{2} \mathrm{O}_{3}\right)$ particles $50 \mu \mathrm{m}$ in diameter, 2.8 bar at a distance of $10 \mathrm{~mm}$ (International Dental Supply, Savona, Italy) (AB); macro-retentive features associated with air abrasion of the post surface with $\mathrm{Al}_{2} \mathrm{O}_{3}$ particles (same procedures as in the MR and $\mathrm{AB}$ groups) (MR+AB).

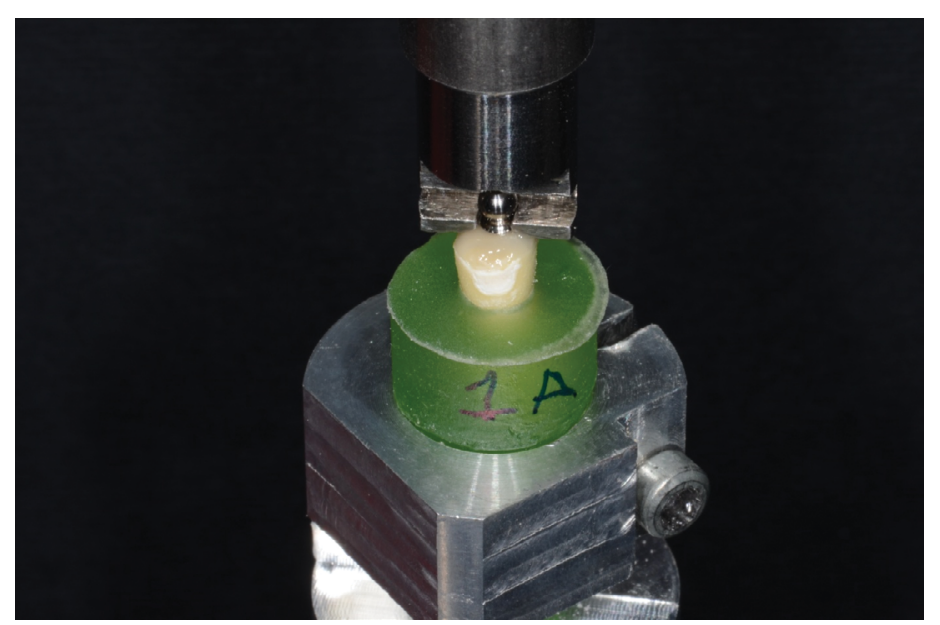

Figure 1. Specimen prepared for to pull out test. It is clearly visible the slot-type engagement system to the ball-attchment sphere. The force is coaxially directed to both titanium post and embedding resin cylinder. 


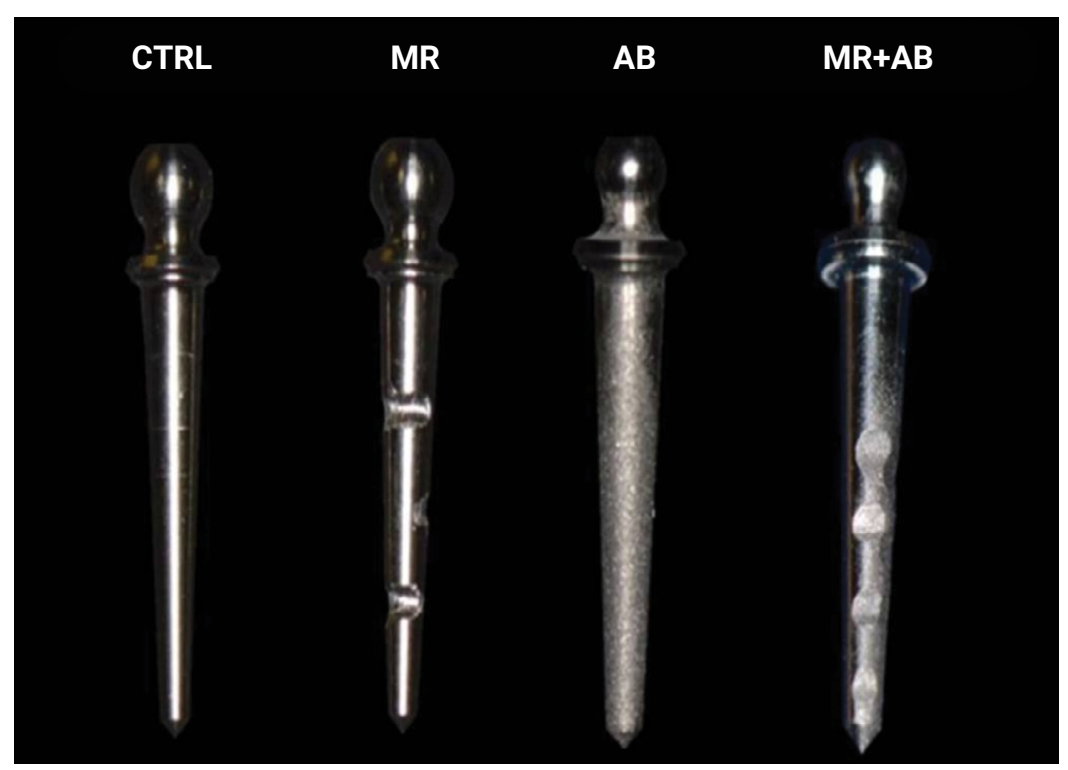

Figure 2. Representative image of the study groups. CTRL: control group, surface without treatment; MR: surface with macro retentions; $A B$ : air-abraded surface; $M R+A B$ macro retentions + air-abraded surface.

All posts were cemented using RelyX Unicem Automix (3M ESPE, St. Paul, MN, USA), a self-adhesive dual resin cement, and photoactivated for $20 \times 2 \mathrm{~s}$ on opposite surfaces, following the manufacture instructions. An alphanumeric code with the letter of the group and the number of the specimen was written on the resin cylinder.

The pull-out test was performed by attaching the post/root/resin assembly to the fixed axis of an universal testing machine (Instron 4301; Instron, Norwood, MA, USA) and and a flexible clamp, connected to the machine traverse, was engaged in the ball-attachment of the post through a slot-type engagement (Fig. 2).

The specimens were tested at a crosshead speed of $0.5 \mathrm{~mm} / \mathrm{min}$ until post detachment and the maximum force ( $\mathrm{N}$ ) was recorded (Fig. 1).

The data were analyzed for normality of distribution using the Kolmogorov-Smirnov test. As the data were normally distributed, one-way analysis of variance (ANOVA) was performed to determine differences in pull-out force measurements. In the case of significant differences, pairwise comparisons were performed using the Bonferroni-Dunn test. In all analyses, $p<0.05$ was taken to indicate statistical significance. Data analysis was performed using StatView software (ver. 5.0.1; SAS Institute, Cary, NC, USA). Weibull analysis was also performed: $m$ (Weibull modulus) represents the reliability of the pull-out values expressing the variation in the retention data, and the size distribution of the flaw population within a structure; $\sigma_{0}$ (characteristic strength), indicates the retention value at which $63.2 \%$ of the specimens survived.

After pull-out testing, the metallic posts were examined under an optical microscope $(\times 10)$ and the failures were classified into six categories (areas), i.e. apical, middle and cervical for both sides of the post, indicated by colouring half of the ball attach- 
ment with a marking pen. For each of the six areas, a value was recorded according to the presence of cement on the post surface, as follows: 0 , metallic surface of the post completely polished (principally cement/post failure); 1 , metallic surface of the post with visible cement (post/cement and dentin/cement mixed failure); 2, metallic surface completely covered with cement (principally dentin/cement failure). For each group, the failure distribution is described by percentages.

\section{Results}

Statistical analyses by one-way ANOVA and the Bonferroni-Dunn test showed that all groups were significantly different from each other when compared (Table 1, $\mathrm{p} \leq 0.0002)$. The highest mean values $(\mathrm{N})$ were found for $A B(485.37 \pm 68.36)$, followed by MR+AB (355.80 \pm 118.47$), M R(224.63 \pm 42.54)$ and Ctrl $(113.12 \pm 51.32)$ (Table 1). Two roots (one in the $A B$ group and one in the MR+AB group) fractured during the test and were excluded from the analysis.

Table 1. Means (Newtons), standard deviations (SD) values of pull out test and Bonferroni/Dunn test; Significance: alpha $=0.05$. All the groups were significantly different from each other.

\begin{tabular}{lcccccc}
\hline \multirow{2}{*}{ Groups } & Mean \pm SD* & \multicolumn{5}{c}{ Bonferroni/Dunn test } \\
\cline { 3 - 7 } & & & Mean Diff. & Crit. Diff & P-value & Significance \\
\hline Control & $113.12 \pm 51.32 \mathrm{D}$ & CTRL-MR & -111.513 & 75.552 & .0002 & $\mathrm{Y}$ \\
\hline $\mathrm{MR}$ & $224.63 \pm 42.54 \mathrm{C}$ & $\mathrm{C}$ CTRL-AB & -372.258 & 76.890 & $<.0001$ & $\mathrm{Y}$ \\
\hline $\mathrm{AB}$ & $485.37 \pm 68.36 \mathrm{~A}$ & $\mathrm{C}$ CTRL-MR+AB & -242.758 & 76.890 & $<.0001$ & $\mathrm{Y}$ \\
\hline $\mathrm{MR}+\mathrm{AB}$ & $355.88 \pm 118.47 \mathrm{~B}$ & MR-AB & -260.745 & 76.890 & $<.0001$ & $\mathrm{Y}$ \\
\hline \multirow{2}{*}{} & & MR-MR+AB & -131.245 & 76.890 & $<.0001$ & $\mathrm{Y}$ \\
\cline { 3 - 7 } & & AB-MR+AB & 129.500 & 78.204 & $<.0001$ & $\mathrm{Y}$ \\
\hline
\end{tabular}

*Different uppercase letters indicate a statistical difference between groups

The Weibull moduli of MR and $A B$ were the highest, while the characteristic strength was highest for $A B$ and $M R+A B$ (Table 2).

Table 2. Weibull analysis of the pull out values.

\begin{tabular}{lcccc}
\hline \multirow{2}{*}{ Groups $^{\mathrm{a}}$} & \multicolumn{4}{c}{ Weibull Analysis $^{\mathrm{b}}$} \\
\cline { 2 - 5 } & $\mathrm{m}$ & $\mathrm{Cl}$ & $\alpha_{0}$ & $\mathrm{Cl}$ \\
\hline Control & 2.25 & $1.29-3.14 \mathrm{BC}$ & 128.16 & $95.87-171.16 \mathrm{c}$ \\
\hline $\mathrm{MR}$ & 6.2 & $3.57-8.65 \mathrm{~A}$ & 242.72 & $218.45-269.59 \mathrm{~b}$ \\
\hline $\mathrm{AB}$ & 7.9 & $4.55-11 \mathrm{~A}$ & 510.67 & $470.1-554.59 \mathrm{a}$ \\
\hline $\mathrm{MR}+\mathrm{AB}$ & 2.95 & $1.66-4.15 \mathrm{C}$ & 406.17 & $322.44-511.98 \mathrm{a}$ \\
\hline
\end{tabular}

aMR: macro retentions; $A B$ : air-abrasion; $M R+A B$ : macro retentions + air-abrasion.

bWeibull analysis for pull out values: $\left(\alpha_{0}\right)$ characteristic resistance in $\mathrm{MPa}$, and $m=$ Weibull modulus $(95 \%$

confidence intervals $[\mathrm{Cl}]$ ). Lowercase letters were used for $\alpha_{0}$ values and capital letters for $m$ values. 
Figure 3 shows the failure distributions after stereomicroscope observation (X10) of the post surface, following the codification described in figure 4.

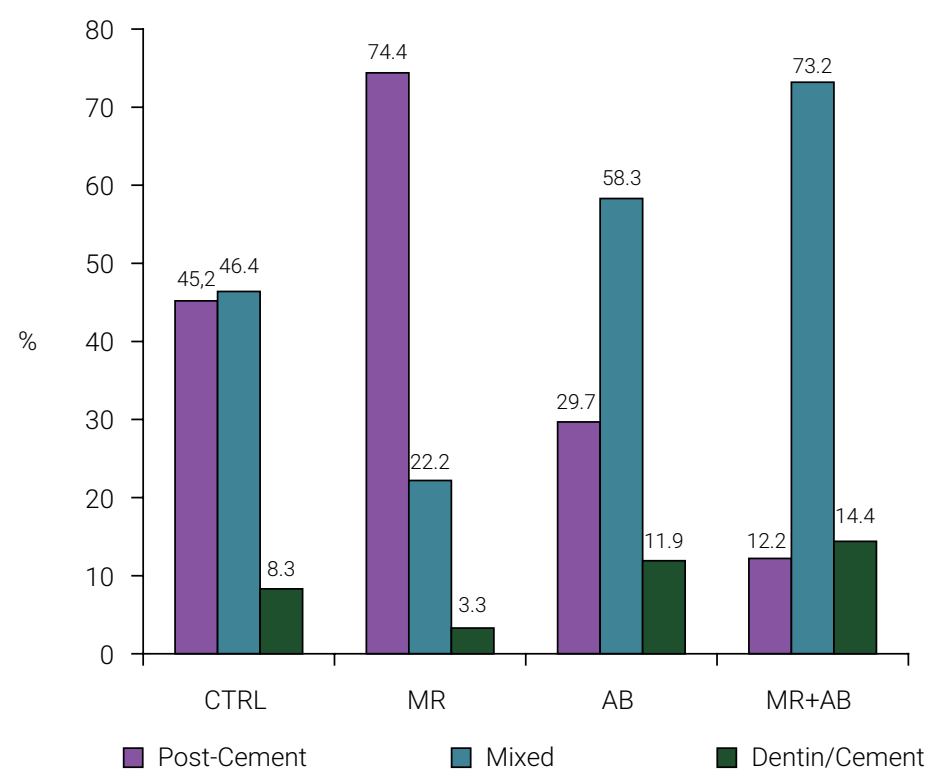

Figure 3. Failure distribution: 90 portions of the control and MR groups, 84 portions of the $A B$ and $M R+A B$ groups were analyzed.

A

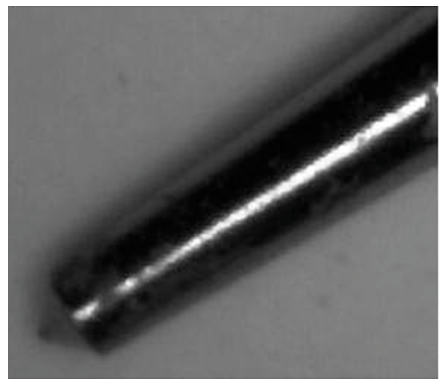

B

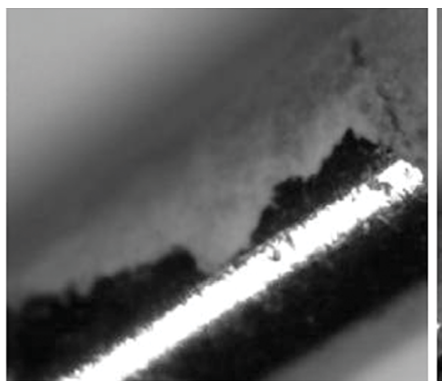

C

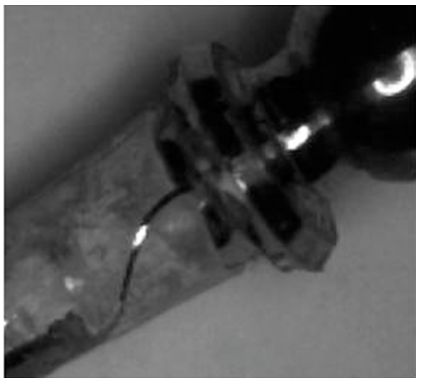

A: Code $0=$ metallic surface of the post completely polished (principally cement/post failure)

$\mathrm{B}$ : Code $1=$ metallic surface of the post with visible cement (post/cement and dentin/cement mixed failure)

C: Code 2 = metallic surface completely covered with cement (principally dentin/cement failure).

Figure 4. Some representative images of the types of failures.

\section{Discussion}

This study was performed to evaluate the retention of spherical attachment titanium posts to dentin and the types of adhesive failure. The null hypothesis, i.e. that there would be no difference in retention value among groups, was rejected because the $A B$ group showed higher values than the other groups. 
The success of intraradicular posts depends on the presence of sufficient adhesive force at the dentin/cement and post/cement interfaces. Resin cements show better performance than other types of cement, but their use is technique-sensitive and requires adequate skill. Therefore, self-adhesive resin cements have been introduced to simplify the clinical procedures and reduce the operation time ${ }^{23}$. Although the initial $\mathrm{pH}$ of composites is approximately 2 ( $\mathrm{pH}$ of RelyX Unicem $<2$ in the first minute), no demineralisation of the dentin or hybrid layer formation has been reported ${ }^{24}$. Monomers show multiple mechanisms of action on dentin; for example, 10-MDP (10-Methacryloyloxydecyl dihydrogen phosphate) widely used in dental cements and adhesives creates nanolayer precipitates that are responsible for the stability and adhesive strength. The infiltration of dentin could be hindered by the high viscosity of the cement. The polymerisation reaction gives rise to the formation of molecules with high molecular weight, while the acid-base reaction with hydroxyapatite increases the $\mathrm{pH}$ up to $7^{25,26}$.

Acid neutralisation occurs due to the bond between phosphate and alkaline groups present in the fillers and hydroxyapatite crystals. This reaction produces water, which renders the cement more hydrophilic and better able to moisten the dentin. Water is fundamental in this adhesive system, as it facilitates the release of hydrogen ions that interact with the hydroxyapatite ${ }^{27}$. The bond between resin cement and the titanium surface is based on two factors: chemical adhesion and micromechanical retention ${ }^{28}$. Three types of pre-treatment on the titanium surface have been shown to increase this bond: promoters of chemical adhesion, promoters of micromechanical retention, and promoters of chemical and micromechanical adhesion.

Specific primers for metals (MEPS, 4-META and later MDP), which react with the oxides present on the surface of titanium, have been used to improve chemical adhe$\operatorname{sion}^{29}$. As alternatives, bifunctional silanes chemically bound to both the resin matrix and the metal have been employed ${ }^{30}$.

However, there have been few studies regarding chemical treatment of intraradicular posts. The most common method used for post preparation is air abrasion with $\mathrm{Al}_{2} \mathrm{O}_{3}$ particles $(30 \mu \mathrm{m}, 50 \mu \mathrm{m}, 110 \mu \mathrm{m}, 250 \mu \mathrm{m})$ to promote micromechanical retention. This treatment increases the adhesive area, decreases the surface tension and increases wettability of the surface ${ }^{31,32}$. Schneider et al. reported that there was no statistically significant difference in retention between cementing posts with dual resin cements at 10 minutes versus 24 hours after air abrasion ${ }^{33}$. This could be due to the ability of the oxide layer to self-limit, acting as a barrier to the reaction between titanium and the environment.

Schmage et al. reported no difference between cementing posts with resin cements and applying air abrasion to their surfaces versus cementing posts with zinc phosphate cement ${ }^{34}$.

A combination of chemical and micromechanical effects was obtained by air abrasion of the post surface with $\mathrm{Al}_{2} \mathrm{O}_{3}$ particles coated with silica $\left(\mathrm{SiO}_{2}\right.$ tribochemical treatment); the particles hit the surface with high energy and develop temperature peaks that melt and deposit silica on the surface, rendering the surface rich in silica so that it reacts with the adhesive materials (silane and resin cements) ${ }^{35}$. However, a positive 
effect on retention is not achieved by all resin cements because they contain different adhesives, e.g. 10-MDP shows reduced bonding on silica surfaces, whereas silanes promote adhesion ${ }^{34}$.

Contrasting results have been found in relation to $\mathrm{Al}_{2} \mathrm{O}_{3}$ particle dimensions. In some studies, higher retention values were achieved using small air abrasion particles compared to larger particles, while other studies showed the opposite result ${ }^{36,37}$. Larger particles likely lead to a rougher titanium surface, thereby increasing the contact area with the cement.

On the other hand, when air abrasion is associated with silanisation, differences in retention due to the different sizes of the air abrasion particles become less significant $^{38}$. In a similar study, Nergiz et al. showed that air-abraded titanium posts with macro-retentions on the surface had higher retention values compared to the Ctrl group, although these posts were cemented with zinc phosphate cement ${ }^{39}$. Furthermore, groups wherein air abrasion was associated with macro-retentions showed a threefold greater mean retention value.

Few studies similar to ours have been reported in the literature and the tested treatments often require more complex or expensive procedures; more generally, the tested specimens were typically titanium plates rather than titanium posts ${ }^{38,40}$.

Regarding the Weibull analysis, $\mathrm{AB}$ and MR showed the highest Weibull modulus $(m)$, indicating that the retention of titanium posts treated with air abrasion or macro-retention had higher reliability than the other treatments. However, in relation to the failure distribution data, MR showed a high percentage of cement/post failures with weaker adhesion at this interface than the dentin/cement interface, unlike the $A B$ group. With regard to characteristic strength $\left(\sigma_{0}\right), A B$ and $M R+A B$ showed the highest values, possibly because these treatments promoted major topographic changes (chemical and mechanical) on the titanium post surface and consequently produced a greater interaction with the resin cement. The failure distribution data confirmed this, as both groups ( $A B$ and $M R+A B)$ showed a higher percentage of mixed failures.

The $M R+A B$ group showed a mean retention value threefold greater than the Ctrl group, while the $A B$ group had a mean value fourfold greater than the Ctrl group. Comparison of our results with those of Nergiz et al. indicated differences between the air abrasion and air abrasion with macro-retention groups ${ }^{39}$. In the present study, the cement may not have been able to penetrate sufficiently into the macro-retentions of the posts, generating defects at the post/dentin interface or due to greater cement thickness. It will be necessary to evaluate the differences in dentin/cement interactions according to failure mode; nevertheless, even with detailed failure analysis, it is difficult to precisely determine which of the two interfaces failed first.

The macro-retentions likely increased retention by strengthening the shear forces on the post/cement interface. However, a completely air-abraded post surface allows better retention at the cement/dentin interface and the presence of macro-retentions is insignificant because they may not overcome the retention threshold at the cement/ dentin interface. 
In conclusion the results of the present study suggested that retention of the Rhein 83 preformed titanium post can be improved by surface pre-treatment prior to cementing with self-adhesive resin cement. These procedures are recommended because the untreated smooth surface does not provide satisfactory results and there is a high risk of detachment. The results suggested that the posts should be air-abraded during the manufacturing stage to ensure a standardised surface treatment and reduce the operation time.

\section{Conflicts of interest}

The authors declare no potential conflict of interests with respect to the authorship and/or publication of this article.

\section{References}

1. Scotti R, Melilli D, Pizzo G. [Overdenture supported by natural teeth: analysis of clinical advantages]. Minerva Stomatol. 2003 May;52(5):201-10. Italian.

2. Melilli D, Davì G, Messina P, Scardina GA. Tooth-implant connection in removable denture. Minerva Stomatol. 2017 Feb;66(1):35-42. doi: 10.23736/S0926-4970.16.03953-9.

3. Scherer MD, Campagni WV. An accelerated clinical chairside technique for casting overdenture attachment copings. J Prosthet Dent. 2011 Nov;106(5):337-9. doi: 10.1016/S0022-3913(11)60141-8.

4. Wang RR, Fenton A. Titanium for prosthodontic applications: a review of the literature. Quintessence Int. 1996 Jun;27(6):401-8.

5. Standlee JP, Caputo AA, Hanson EC. Retention of endodontic dowels: effects of cement, dowel length, diameter, and design. J Prosthet Dent. 1978 Apr;39(4):400-5. doi: 10.1016/s0022-3913(78)80156-5.

6. Miller AW 3rd. Post and core systems: which one is best? J Prosthet Dent. 1982 Jul;48(1):27-38. doi: 10.1016/0022-3913(82)90043-9.

7. Kurer HG, Combe EC, Grant AA. Factors influencing the retention of dowels. J Prosthet Dent. 1977 Nov;38(5):515-25. doi: 10.1016/0022-3913(77)90026-9.

8. Nergiz I, Schmage P, Platzer U, McMullan-Vogel CG. Effect of different surface textures on retentive strength of tapered posts. J Prosthet Dent. 1997 Nov;78(5):451-7. doi: 10.1016/s0022-3913(97)70059-3.

9. Tjan AH, Whang SB. Retentive properties of some simplified dowel-core systems to cast gold dowel and core. J Prosthet Dent. 1983 Aug;50(2):203-6. doi: 10.1016/0022-3913(83)90014-8.

10. Robbins JW. Guidelines for the restoration of endodontically treated teeth. J Am Dent Assoc. 1990 May;120(5):558, 560, 562 passim. doi: 10.14219/jada.archive.1990.0087.

11. Tjan $A H, T j a n A H$, Greive JH. Effects of various cementation methods on the retention of prefabricated posts. J Prosthet Dent. 1987 Sep;58(3):309-13. doi: 10.1016/0022-3913(87)90046-1.

12. Ben-Amar A, Gontar G, Fitzig S, Urstein M, Liberman R. Retention of prefabricated posts with dental adhesive and composite. J Prosthet Dent. 1986 Dec;56(6):681-4. doi: 10.1016/0022-3913(86)90143-5.

13. Assif D, Bleicher S. Retention of serrated endodontic posts with a composite luting agent: effect of cement thickness. J Prosthet Dent. 1986 Dec;56(6):689-91. doi: 10.1016/0022-3913(86)90145-9.

14. Mendoza DB, Eakle WS. Retention of posts cemented with various dentinal bonding cements. J Prosthet Dent. 1994 Dec;72(6):591-4. doi: 10.1016/0022-3913(94)90290-9. 
15. Cohen BI, Pagnillo MK, Newman I, Musikant BL, Deutsch AS. Retention of three endodontic posts cemented with five dental cements. J Prosthet Dent. 1998 May;79(5):520-5. doi: 10.1016/s0022-3913(98)70172-6.

16. Duncan JP, Pameijer $\mathrm{CH}$. Retention of parallel-sided titanium posts cemented with six luting agents: an in vitro study. J Prosthet Dent. 1998 Oct;80(4):423-8. doi: 10.1016/s0022-3913(98)70006-X.

17. Standlee JP, Caputo AA. Endodontic dowel retention with resinous cements. J Prosthet Dent. 1992 Dec;68(6):913-7. doi: 10.1016/0022-3913(92)90550-t.

18. Rosenstiel SF, Land MF, Crispin BJ. Dental luting agents: A review of the current literature. J Prosthet Dent. 1998 Sep;80(3):280-301. doi: 10.1016/s0022-3913(98)70128-3.

19. Balbosh A, Ludwig K, Kern M. Comparison of titanium dowel retention using four different luting agents. J Prosthet Dent. 2005 Sep;94(3):227-33. doi: 10.1016/j.prosdent.2005.05.025.

20. Li ZC, White SN. Mechanical properties of dental luting cements. J Prosthet Dent. 1999 May;81(5):597-609. doi: 10.1016/s0022-3913(99)70216-7.

21. ISO: 11405. Dental Materials - Testing of adhesion to tooth structure. Geneva: International Organization for Standardization; 2003.

22. Piwowarczyk A, Lauer HC. Mechanical properties of luting cements after water storage. Oper Dent. 2003 Sep-Oct;28(5):535-42.

23. De Munck J, Vargas M, Van Landuyt K, Hikita K, Lambrechts P, Van Meerbeek B. Bonding of an auto-adhesive luting material to enamel and dentin. Dent Mater. 2004 Dec;20(10):963-71. doi: 10.1016/j.dental.2004.03.002.

24. Han L, Okamoto A, Fukushima M, Okiji T. Evaluation of physical properties and surface degradation of self-adhesive resin cements. Dent Mater J. 2007 Nov;26(6):906-14. doi: 10.4012/dmj.26.906.

25. Ferracane JL, Stansbury JW, Burke FJ. Self-adhesive resin cements - chemistry, properties and clinical considerations. J Oral Rehabil. 2011 Apr;38(4):295-314. doi: 10.1111/j.1365-2842.2010.02148.x..

26. Radovic I, Monticelli F, Goracci C, Vulicevic ZR, Ferrari M. Self-adhesive resin cements: a literature review. J Adhes Dent. 2008 Aug;10(4):251-8.

27. Tsuchimoto $Y$, Yoshida $Y$, Takeuchi M, Mine A, Yatani H, Tagawa Yet al. Effect of surface pre-treatment on durability of resin-based cements bonded to titanium. Dent Mater. 2006 Jun;22(6):545-52. doi: 10.1016/j.dental.2005.08.002.

28. Yoshida K, Taira Y, Matsumura H, Atsuta M. Effect of adhesive metal primers on bonding a prosthetic composite resin to metals. J Prosthet Dent. 1993 Apr;69(4):357-62. doi: 10.1016/0022-3913(93)90180-v.

29. Matinlinna JP, Lassila LV, Vallittu PK. The effect of five silane coupling agents on the bond strength of a luting cement to a silica-coated titanium. Dent Mater. 2007 Sep;23(9):1173-80. doi: 10.1016/j.dental.2006.06.052.

30. Kern M, Thompson VP. Sandblasting and silica-coating of dental alloys: volume loss, morphology and changes in the surface composition. Dent Mater. 1993 May;9(3):151-61. doi: 10.1016/0109-5641(93)90113-5.

31. Kern M, Thompson VP. Effects of sandblasting and silica-coating procedures on pure titanium. J Dent. 1994 Oct;22(5):300-6. doi: 10.1016/0300-5712(94)90067-1.

32. Schneider R, de Goes MF, Henriques GE, Chan DC. Tensile bond strength of dual curing resin-based cements to commercially pure titanium. Dent Mater. 2007 Jan;23(1):81-7. doi: 10.1016/j.dental.2005.12.006.

33. Schmage P, Sohn J, Ozcan M, Nergiz I. Effect of surface treatment of titanium posts on the tensile bond strength. Dent Mater. 2006 Feb;22(2):189-94. doi: 10.1016/j.dental.2005.04.015. 
34. Thompson JY, Stoner BR, Piascik JR, Smith R. Adhesion/cementation to zirconia and other non-silicate ceramics: where are we now? Dent Mater. 2011 Jan;27(1):71-82. doi: 10.1016/j.dental.2010.10.022.

35. Papadopoulos T, Tsetsekou A, Eliades G. Effect of aluminium oxide sandblasting on cast commercially pure titanium surfaces. Eur J Prosthodont Restor Dent. 1999 Mar;7(1):15-21.

36. Watanabe I, Kurtz KS, Kabcenell JL, Okabe T. Effect of sandblasting and silicoating on bond strength of polymer-glass composite to cast titanium. J Prosthet Dent. 1999 Oct;82(4):462-7 doi: 10.1016/s0022-3913(99)70035-1.

37. de Almeida-Júnior AA, Fonseca RG, Haneda IG, Abi-Rached Fde O, Adabo GL. Effect of surface treatments on the bond strength of a resin cement to commercially pure titanium. Braz Dent J. 2010;21(2):111-6. doi: 10.1590/s0103-64402010000200004.

38. Nergiz I, Schmage P, Platzer U, McMullan-Vogel CG. Effect of different surface textures on retentive strength of tapered posts. J Prosthet Dent 1997 vol 78;5:451-7.

39. Elsaka SE, Swain MV. Effect of surface treatments on the adhesion of self-adhesive resin cements to titanium. J Adhes Dent. 2013 Feb;15(1):65-71. doi: 10.3290/j.jad.a27827. 